\title{
Comparison of First 50 and Subsequent 74 Surgeries of Transcanalicular Laser Dacryocystorhinostomy Performed by a Surgeon Team
}

\author{
Eyyup Karahan', Ibrahim Tuncer ${ }^{2 *}$, \\ Duygu Er ${ }^{3}$, Burak Ulkumen 4 \\ ${ }^{1}$ Department of Ophthalmology, Sifa University, Izmir, Turkey \\ ${ }^{2}$ Alfagoz Eye Center, Izmir, Turkey \\ ${ }^{3}$ Department of Ophthalmology, Dokuz Eylul University, Balçova/İzmir, Turkey \\ ${ }^{4}$ Department of Otorhinolaryngology, Celal Bayar University, Manisa, Turkey \\ Email: *ibrahimtuncer106@gmail.com
}

Received 20 February 2016; accepted 3 May 2016; published 6 May 2016

Copyright (C 2016 by authors and Scientific Research Publishing Inc.

This work is licensed under the Creative Commons Attribution International License (CC BY).

http://creativecommons.org/licenses/by/4.0/

\section{(c) (i) Open Access}

\section{Abstract}

Purpose: To compare perioperative and postoperative outcomes of the first and following 50 cases of transcanalicular laser dacryocystorhinostomy performed by a surgeon team. Methods: Results of 124 eyes of 115 patients who had a diagnosis of distal obstruction of the lacrimal drainage system and underwent transcanalicular laser dacryocystorhinostomy procedures were retrospectively detected. Initial 50 eyes were considered as group 1; 74 following eyes were accepted as group 2. Groups were compared regarding age, gender, total surgical time, time for creation of osteotomy, pain score, bleeding score, anatomic and functional success rates. Results: The average total surgical time was $43.2 \pm 6.0$ minutes (range: 31 to 65 minutes) in group 1 , and $30.0 \pm 6.4$ minutes (range: 21 to 57 minutes) in group $2(p<0.001)$. Laser osteotomy creation required $25.0 \pm$ 4.2 minutes (range: 14 to 34 minutes) in group 1, and $14.6 \pm 3.6$ months (range: 9 to 28 minutes) $(p<0.001)$. Intraoperative pain and bleeding scores were significantly better in group $2(p<0.001$ and $p<0.001$ respectively). Success rate was $54.0 \%$ in group 1 , and $85.1 \%$ in group $2(p<0.001)$. Conclusion: The results of current study clearly showed that increased experience of a surgeon results with improvement of better surgical outcomes. Initial studies about a novel technique should make clear if the study cases are the beginning cases of the authors.

\footnotetext{
"Corresponding author.
}

How to cite this paper: Karahan, E., Tuncer, I., Er, D. and Ulkumen, B. (2016) Comparison of First 50 and Subsequent 74 Surgeries of Transcanalicular Laser Dacryocystorhinostomy Performed by a Surgeon Team. Open Journal of Ophthalmology, 6, 80-85. http://dx.doi.org/10.4236/ojoph.2016.62011 


\section{Keywords}

Transcanalicular Laser Dacryocystorhinostomy, Learning Curve, Surgical Outcomes

\section{Introduction}

Nasolacrimal duct obstruction (NLDO) with symptomatic epiphora is a common disorder that presents to the ophthalmologists. Dacryocystorhinostomy (DCR) is the definitive treatment, in which the patency of the blocked lacrimal outflow system is reestablished with the creation of a fistula for direct communication of the nasolacrimal sac and the nasal cavity.

In treatment of patients with primary acquired NLDO, external DCR is accepted as gold standard. Dacryocystorhinostomy was first described by Toti in 1904 as an external approach to the sac through a skin incision in the medial canthus, and there is a wide experience with external DCR throughout of the world. For treatment of these patients, alternative techniques to external DCR have been applied such as balloon catheter dilatation, endonasal DCR and transcanalicular laser DCR (TLDCR).

In 1990, Massaro et al. introduced endonasal laser DCR using a high-energy argon laser device [1]. Transcanalicular laser dacryocystorhinostomy was first introduced by Levin et al. using cadavers in 1992 [2]. A range of success rates have been reported for TLDCR, and although several have reported comparable results with external and endonasal DCR, the success rates have been tended to be lower in TLDCR when compared with external and endonasal DCR for TLDCR [3]-[12]. However, TLDCR is a relatively novel technique and most of the studies about this technique have reported the initial experiences. As with all novel techniques, a learning curve is suggested with one group of noting improvement in success rates from $50 \%$ in the first 38 cases to $79 \%$ in the last 38 cases [7].

The aim of this study was to compare perioperative and postoperative outcomes of the initial and following cases of endolaser DCR performed by a surgeon team.

\section{Methods}

A retrospective chart review was performed to the patients of an ophthalmologist (E.K) and an otorhinolaryngologist (B.U) at one secondary surgical center (Deniz Hospital, Izmir, Turkey) April 2011 and January 2014. The study center has an average admission of 100 patients per year with obstruction of the lacrimal drainage system. The study protocol was adhered to the tenets of the Declaration of Helsinki. During this time, 134 eyes of 125 patients who had a diagnosis of distal obstruction of the lacrimal drainage system underwent TLDCR procedures. Fifty-five eyes of 51 patients that were initial experiences of the surgeon team were considered as group 1, 79 eyes of 74 patients operated after initial cases were accepted as group 2 .

The patients ophthalmic and nose examinations were done before surgery. The NLDO was diagnosed by nasolacrimal irrigation. Cases with the presence of intrasaccular adhesions, common canalicular stenosis, acute dacryocystitis, recurrent dacryostenosis, paediatric cases, canalicular stenosis, lacrimal sac neoplasms, dacryolithiasis, fistulous dacryostenosis, predominant bone deformities (posttraumatic or lacrimal sac fossa deformities) and additional intranasal abnormalities were excluded from the study. The patients with follow-up time shorter than 180 days were also excluded from the study. All operations were carried out by the transcanalicular diodelaser (Biolase, San Clemente. CA). All patients were operated under regional anesthesia. Thirty minutes before the surgical intervention, $10 \%$ xylocaineand adrenaline-absorbed cotton plugs were applicated into the nasal cavity. After the evacuation of the plugs, the patients underwent blockage of medial canthal and anterior ethmoid region. Adrenaline $(1 / 100,000)$ added to lidocaine solution was injected intranasally to the middle turbinate, 1 $\mathrm{cm}$ anterior to the insertion point of the middle turbinate. Topical ophthalmic anesthesia was achieved by $0.5 \%$ proparacaine hydrochloride. The inferior and superior puncta were dilated, and a 600-Km laser fiber proceeded through the canaliculi up to the sac. A 4-mm 30-degree angled rigid nasal endoscope was introduced into the nasal cavity. The aiming beam was identified transmucosally. Under endoscopic guidance, continuous wave contact laser energy was used, and the lacrimal bone and the nasal mucosa were evaporated. By the forward and backward movements of the fiber optic, the osteotomy site was enlarged. After the withdrawal of the laser fiber, the operation site was irrigated with saline solution. Then, silicone tube was applicated, and the free ends of the 
tube were knotted within the nasal cavity.

After surgery the patient was allowed to return home and was instructed to use a nasal wash with physiological saline or with 3 percent hypertonic saline, oxymetazoline as nasal drops for 1 week, and eye drops containing dexamethasone, and moxifloxacin for 1 week.

Surgical time was measured from the beginning of the anesthetic procedure to the end of the intervention. Intraoperative bleeding was subjectively evaluated by the surgeon and classified as absent, no need for aspiration; mild, few aspirations; moderate, need to interrupt the procedure and reinforce vasoconstriction with cotton soaked in oxymetazoline; and severe, need to stop the procedure. Pain was evaluated intraoperatively by the surgeon who assigned a subjective score according to patient reactions during surgery: 1 , absence of manifestations of pain; 2, manifestations of pain that did not interfere with the procedure; 3 , need for reinforced local anesthesia.

Fistula permeability and absence of initial symptoms were evaluated 7, 30, 60, and 180 days after surgery. Success was defined by resolution of symptoms (epiphora or discharge) or by unobstructed lacrimal irrigation. Due to the moderately invasive nature of lacrimal irrigation, patients who were symptom-free were not routinely irrigated.

SPSS, statistical software, version 11.6 (SPSS, Inc., Chicago, IL, USA) was used for statistical analysis. Data were analyzed by analysis of Independent Samples "T" test, the categorical variables between the groups were analysed by using $\chi^{2}$ test. P value of less than 0.05 was considered statistically significant.

\section{Results}

Five patients from group 1 and 5 patients from group 2 were excluded from the study because of missed follow-up. Thirty-nine (84.7\%) of the 46 patients were female in group1, 57 patients (82.6\%) were female in group 2. Mean age of group 1 was $59.9 \pm 10.2$ years (range: 26 to 81 years), mean age was $61.1 \pm 7.9$ (range: 29 to 76 years) in group 2 . There was no difference between groups regarding gender and age ( $p=0.444, p=0.115$, respectively). The average total surgical time was $43.2 \pm 6.0$ minutes (range: 31 to 65 minutes) in group 1, and $30.0 \pm 6.4$ minutes (range: 21 to 57 minutes) in group $2(\mathrm{p}<0.001)$. Laser osteotomy creation required $25.0 \pm$ 4.2 minutes (range: 14 to 34 minutes) in group 1, and $14.6 \pm 3.6$ minutes (range: 9 to 28 minutes) in group 2 (p < $0.001)$.

The intraoperative pain score was 1 for 6 eyes (12.0\%), 2 for 18 eyes (36.0\%), 3 for 26 eyes (52.0\%) in group 1. Pain score was 1 for 26 eyes (35.1\%), 2 for 38 eyes (51.3\%), 3 for 10 eyes (13.6\%) in group 2. Pain score was significantly better in group $2(\mathrm{p}<0.001)$.

Intraoperative bleeding was absent in 7 eyes (14.0\%), mild in 18 eyes (36.0\%), and moderate in 25 eyes (50.0\%) in group 1, intraoperative bleeding was absent in 21 eyes (28.3\%), mild in 44 eyes (59.5\%), moderate in 9 eyes (12.2\%) in group 1, interruption of the procedure because of bleeding did not required in any eye. Intraoperative bleeding score was significantly better in group $2(\mathrm{p}<0.001)$.

Twenty-three eyes were failed based on recurrent symptoms or reflux on nasolacrimal irrigation ( $54.0 \%$ success) in group 1, 11 eyes were failed (85.1\% success) in group $2(\mathrm{p}<0.001)$ (Table 1$)$.

Table 1. Comparement of group 1 and group 2 in regard to surgical results.

\begin{tabular}{|c|c|c|c|}
\hline & Group 1 & Group 2 & $\mathrm{P}$ value \\
\hline Total surgical time (minutes) & $43.2 \pm 6.0$ & $30.0 \pm 6.4$ & $<0.001$ \\
\hline Laser osteotomy creation time (minutes) & $25.0 \pm 4.2$ & $14.6 \pm 3.6$ & $<0.001$ \\
\hline \multicolumn{4}{|l|}{ Intraoperative pain score (\%) } \\
\hline 1 & 12.0 & 35.1 & \\
\hline 2 & 36.0 & 51.3 & $<0.001$ \\
\hline 3 & 52.0 & 13.6 & \\
\hline \multicolumn{4}{|l|}{ Intraoperative bleeding score } \\
\hline Absent & 14.0 & 28.3 & \\
\hline Mild & 36.0 & 59.5 & $<0.001$ \\
\hline Moderate & 50.0 & 12.2 & \\
\hline Success rate & 54.0 & 85.1 & $<0.001$ \\
\hline
\end{tabular}




\section{Discussion}

The history of DCR is well known and has been retold frequently. The exceptionally successful external approach has remained essentially unaltered since its inception, with the notable introduction of mucosal linings by Dupuy-Dutemps and Bourguet in 1912 and concurrent silicone intubation by Jones in 1962 [13]. There is little dispute that external DCR affords the greatest likelihood of resolving epiphora due to complete lacrimalduct obstruction when compared with endoscopic surgical approaches.

Endonasal DCR has recently gained popularity because it avoids skin incision. Transcanalicular laser DCR represents an attempt to improve on endonasal lacrimal surgery by creating the ostium from the lacrimal side via intubation of the canaliculus with a fiber-optic laser [14]. Furthermore, TLDCR has been associated with less bleeding, a more controlled formation of the ostium, shorter operating time, and faster patient recovery. Success rates for TLDCR, however, are reported between 73\% and 88\% [3]-[12] [15]-[17].

To date, the major drawback of TLDCR has been the inferiority of outcomes when compared with standard external DCR. Some methods for improving the success rates of TLDCR were performed by some authors. Good anatomical results and symptom resolution were demonstrated in $89 \%$ of eyes and $86 \%$ of patients following endocanalicular laser DCR with mucosal flap creation [18]. Another study performed multiple postoperative applications of MMC and concluded that MMC was safe and effective adjunctive modality after TLDCR with a success rate of 92.8\% in primary acquired nasolacrimal duct obstruction [19]. Basmak et al. [20] have demonstrated improved outcomes in patients treated with TLDCR and partial anterior middle turbinectomy compared with those with TLDCR alone. In this study, anatomical success and functional success were improved from $76 \%$ to $94 \%$ and $71 \%$ to $88 \%$, respectively, with the addition of middle turbinectomy.

Transcanalicular laser DCR is a very newly used method when compared with external or endonasal DCR. More recent studies report favorable results that are comparable with external DCR and endonasal DCR [15]-[17] [20]-[28]. We believe that most of the studies in the literature are the results of primary cases and the improvement of the success rates in more recent studies might be due to having more experience in this novel surgery. In our study, we compared the initial 50 eyes and following 74 eyes operated with TLDCR by same surgical team.

Postoperative surgical success rates were significantly better in following 74 eyes when compared with initial 50 eyes. Total surgical time and time for creation of osteotomy were significantly shorter in following 74 eyes. Pain and bleeding scores were also better in these cases when compared with initial 50 cases.

The main weakness of this study is its small sample size. The other limitation is short follow-up time. Such studies should extend follow-up until at least 2 years to account for the possibility of late failures. Larger sample size and longer follow-up time are needed to strengthen the value of further studies.

The results of current study clearly showed that increased experience of a surgeon results with improvement of better surgical outcomes. We believe that comparing the initial cases with next cases will be very useful to learn the causes of failure in the initial cases especially in a novel technique. Initial studies about a novel technique should make clear that if the study cases are the beginning cases of the authors.

\section{Financial Disclosure}

No author has a financial or proprietary interest in any material or method mentioned.

\section{References}

[1] Massaro, B.M., Gonnering, R.S. and Harris, G.J. (1990) Endonasal Laser Dacryocystorhinostomy: A New Approach to Nasolacrimal Duct Obstruction. Archives of Ophthalmology, 108, 1172-1176. http://dx.doi.org/10.1001/archopht.1990.01070100128048

[2] Levin, P.S. and Stormogipson, D.J. (1992) Endocanalicular Laser-Assisted Dacryocystorhinostomy. An Anatomic Study. Archives of Ophthalmology, 110, 1488-1490. http://dx.doi.org/10.1001/archopht.1992.01080220150037

[3] Woog, J.J., Metson, R. and Puliafito, C.A. (1993) Holmium:YAG Endonasal Laser Dacryocystorhinostomy. American Journal of Ophthalmology, 116, 1-10. http://dx.doi.org/10.1016/S0002-9394(14)71736-2

[4] Ressiniotis, T., Voros, G.M., Kostakis, V.T., et al. (2005) Clinical Outcome of Endonasal KTP Laser Assisted Dacryocystorhinostomy. BMC Ophthalmology, 5, 2. http://dx.doi.org/10.1186/1471-2415-5-2

[5] Maini, S., Raghava, N., Youngs, R., et al. (2007) Endoscopic Endonasal Laser versus Endonasal Surgical Dacryocystorhinostomy for Epiphora Due to Nasolacrimal Duct Obstruction: Prospective, Randomized, Controlled Trial. The Journal of Laryngology \& Otology, 121, 1170-1176. http://dx.doi.org/10.1017/S0022215107009024 
[6] Lester, S.E., Robson, A.K. and Bearn, M. (2008) Endoscopic 'Cold Steel’ versus Laser Dacryocystorhinostomy: Completing the Audit Cycle. The Journal of Laryngology \& Otology, 122, 924-927. http://dx.doi.org/10.1017/S0022215107001363

[7] Mirza, S., Al-Barmani, A., Douglas, S.A., et al. (2002) A Retrospective Comparison of Endonasal KTP Laser Dacryocystorhinostomy versus External Dacryocystorhinostomy. Clinical Otolaryngology and Allied Sciences, 27, 347-351. http://dx.doi.org/10.1046/j.1365-2273.2002.00593.x

[8] Moore, W.M., Bentley, C.R. and Olver, J.M. (2002) Functional and Anatomic Results after Two Types of Endoscopic Endonasal Dacryocystorhinostomy: Surgical and Holmium Laser. Ophthalmology, 109, 1575-1582. http://dx.doi.org/10.1016/S0161-6420(02)01114-4

[9] Ibrahim, H.A., Batterbury, M., Banhegyi, G. and McGalliard, J. (2001) Endonasal Laser Dacryocystorhinostomy and External Dacryocystorhinostomy Outcome Profile in a General Ophthalmic Service Unit: A Comparative Retrospective Study. Ophthalmic Surgery and Lasers, 32, 220-227.

[10] Camara, J.G. and Santiago, M.D. (1999) Success Rate of Endoscopic Laser-Assisted Dacryocystorhinostomy. Ophthalmology, 106, 441-442. http://dx.doi.org/10.1016/S0161-6420(99)90142-2

[11] Umapathy, N., Kalra, S., Skinner, D.W. and Dapling, R.B. (2006) Long-Term Results of Endonasal Laser Dacryocystorhinostomy. Otolaryngology—Head and Neck Surgery, 135, 81-84. http://dx.doi.org/10.1016/j.otohns.2006.02.006

[12] Tripathi, A., Lesser, T.H., O’Donnell, N.P. and White, S. (2002) Local Anaesthetic Endonasal Endoscopic Laser Dacryocystorhinostomy: Analysis of Patients’ Acceptability and Various Factors Affecting the Success of This Procedure. Eye, 16, 146-149. http://dx.doi.org/10.1038/sj/eye/6700083

[13] Jones, L.T. (1962) The Cure of Epiphora Due to Canalicular Disorders, Trauma and Surgical Failures on the Lacrimal Passages. American Academy of Ophthalmology and Otolaryngology, 66, 506-524.

[14] Vagefi, M.R., Winn, B.J., Lin, C.C., et al. (2009) Facial Nerve İnjury during External Dacryocystorhinostomy. Ophthalmology, 116, 585-590. http://dx.doi.org/10.1016/j.ophtha.2008.09.050

[15] Hong, J., Hatton, M., Leib, M. and Fay, A. (2005) Endocanalicular Laser Dacryocystorhinostomy. Ophthalmology, 112, 1629-1633. http://dx.doi.org/10.1016/j.ophtha.2005.04.015

[16] Drnovsek-Olup, B. and Beltram, M. (2010) Transcanalicular Diode Laser-Assisted Dacryocystorhinostomy. Indian Journal of Ophthalmology, 58, 213-217. http://dx.doi.org/10.4103/0301-4738.62646

[17] Plaza, G., Beteré, F. and Nogueira, A. (2007) Transcanalicular Dacryocystorhinostomy with Diode Laser: Long-Term Results. Ophthalmic Plastic \& Reconstructive Surgery, 23, 179-182. http://dx.doi.org/10.1097/IOP.0b013e31804bdef9

[18] Robert, M.C., Maleki, B. and Boulos, P.R. (2013) Endocanalicular Laser Dacryocystorhinostomy with Mucosal Flaps. Ophthalmic Plastic \& Reconstructive Surgery, 29, 294-297. http://dx.doi.org/10.1097/IOP.0b013e318295f903

[19] Henson, R.D., Cruz, H.L., Henson Jr, R.G., Ali, M.J. and Kakizaki, H. (2012) Postoperative Application of Mitomycin-C in Endocanalicular Laser Dacryocystorhinostomy. Ophthalmic Plastic \& Reconstructive Surgery, 28, $192-195$. http://dx.doi.org/10.1097/IOP.0b013e31824a48f3

[20] Basmak, H., Cakli, H., Sahin, A., Gursoy, H., Ozer, A. and Colak, E. (2011) What İs the Role of Partial Middle Turbinectomy in Endocanalicular Laser Assisted Endonasal Dacryocystorhinostomy? American Journal of Rhinology \& Allergy, 25, 160-165. http://dx.doi.org/10.2500/ajra.2011.25.3598

[21] Gupta, S.K., Kumar, A., Agarwal, S. and Pandey, P. (2012) Transcanalicular Laser Dacryocystorhinostomy Using Low Energy 810 nm Diode Laser. Oman Journal of Ophthalmology, 5, 171-174. http://dx.doi.org/10.4103/0974-620X.106101

[22] Yener, H.I., Gul, A., Caglar, C. and Ozcimen, M. (2014) The Effectiveness of Postoperative Early Ostium Cleaning in Transcanalicular Diode Laser-Assisted Dacryocystorhinostomy. Ophthalmic Plastic \& Reconstructive Surgery, 30, 476-479. http://dx.doi.org/10.1097/IOP.0000000000000137

[23] Henson, R.D., Henson Jr, R.G., Cruz Jr, H.L. and Camara, J.G. (2007) Use of the Diode Laser with İntraoperative Mitomycin C in Endocanalicular Laser Dacryocystorhinostomy. Ophthalmic Plastic \& Reconstructive Surgery, 23, 134137. http://dx.doi.org/10.1097/IOP.0b013e31802f208d

[24] Dogan, R., Meric, A., Ozsütcü, M. and Yenigun, A. (2013) Diode Laser-Assisted Endoscopic Dacryocystorhinostomy: A Comparison of Three Different Combinations of Adjunctive Procedures. European Archives of Oto-Rhino-Laryngology, 270, 2255-2261. http://dx.doi.org/10.1007/s00405-013-2351-1

[25] Taşkıran, A.C., Karadağ, O., Arıkan, S., Gencer, B. and Kara, S. (2014) Comparison of Transcanalicular Diode Laser Dacryocystorhinostomy and External Dacryocystorhinostomy in Patients with Primary Acquired Nasolacrimal Duct Obstruction. Lasers in Surgery and Medicine, 46, 275-280. http://dx.doi.org/10.1002/lsm.22236

[26] Cakmak, S.S. and Yildirim, M. (2010) Use of Endocanalicular Dacryocystorhinostomy with Multidiode Laser in Children. International Journal of Pediatric Otorhinolaryngology, 74, 320-322. 
http://dx.doi.org/10.1016/j.ijporl.2010.08.015

[27] Derya, K., Demirel, S., Doganay, S., Orman, G., Cumurcu, T. and Gunduz, A. (2013) Endoscopic Transcanalicular Diode Laser Dacryocystorhinostomy: Is It an Alternative Method to Conventional External Dacryocystorhinostomy? Ophthalmic Plastic \& Reconstructive Surgery, 29, 15-17. http://dx.doi.org/10.1097/IOP.0b013e31826b76a4

[28] Yeniad, B., Uludag, G. and Kozer-Bilgin, L. (2012) Assessment of Patient Satisfaction Following External versus Transcanalicular Dacryocystorhinostomy with a Diode Laser and Evaluation If Change in Quality of Life after Simultaneous Bilateral Surgery in Patients with Bilateral Nasolacrimal Duct Obstruction. Current Eye Research, 37, $286-292$. http://dx.doi.org/10.3109/02713683.2012.658488 